\title{
Kindness counts: encouraging empathy in secondary school library programs
}

\author{
Molly Foust \\ Shayma Ahkmed \\ The Gulf English Secondary School \\ Doha, Qatar \\ Molly.Foust@gulfenglishschool.com
}

\begin{abstract}
What is the role of the school library in creating a compassionate school culture? How can we forge a stronger connection between empathy and literacy? Why are libraries the best place to teach the communication skills that facilitate empathy? Inspired by recent research proving the connection between literacy and empathy (Castano and Comer 2013), we decided to make empathy a priority in our library services.

Our two primary goals were to 1) create literacy-based programs that would encourage empathy 2) to encourage the exhibition of empathetic behaviors by training a library volunteer corps. We designed simple activities to encourage both empathy and literacy simultaneously. Our anecdotal survey positively reflected that students and staff noticed a more caring, empathetic library environment.
\end{abstract}

KEYWORDS: empathy, international secondary school, literacy and empathy, school library programs 


\section{The international school library: an important place to start caring}

The international school library is an important place to develop a compassionate school culture. By virtue of its contents, it already considers viewpoints from multiple viewpoints and disciplines. By virtue of its size, it allows for team teaching and intermingling of students and staff outside their normal classroom routine. And by virtue of the librarians who care for it, the library already espouses values, such as freedom of speech and a love of knowledge, that support and promote empathy.

School librarians who value intellectual freedom and literacy support values that encourage a reflective and democratic world. In disseminating a variety of ideas we are allowing patrons to reach more informed conclusions that are less likely to be biased, and in providing students with recreational fictional texts we are giving students the opportunity to imagine the life of someone else outside the context of grades and rewards.

Additionally, the library is a neutral environment for staff and students to gather and learn together. In an international environment, where heterogeneity is the norm, it is imperative that libraries support staff and students to model peaceful, tolerant global communities. We have found that both staff and students, either by inclination or frequently due to language barriers, seek out familiar companionship. In some situations, the very differences that make an international learning environment so valuable can also be the cause of tension and intolerance. We sought to improve the relationships between students and between staff with library programming at our international school in Doha, Qatar during the 2013-2014 school year, and were encouraged by anecdotal praise and by survey results taken by staff that showed that $96 \%$ of respondents felt that the library explicitly supported empathy.

\section{Qatari Culture}

The majority of our students are Qatari. Qatar is a small, wealthy gulf nation bordering Saudi Arabia. Our school also contains students from many other parts of the world. Most are affluent. Boys and girls are segregated but share some of the same spaces. Despite being the wealthiest nation in the world, there are only a few bookstores and they are poorly stocked. 
However, we wanted to make empathy as culturally relevant for our students as possible. Since empathy is focused within large, close, extended family groups, many of our book promotion programs emphasized discussing books and reading within the family or with friends. Qataris also follow a conservative branch of Islam, so we used examples from the Koran where possible and made connections for the students between charity and imagining the plight of another. For example, when students showed unkindness towards stray cats, we emphasized that Mohammed had a tabby cat that he loved, and suggested books such as Erin Hunter's Warriors series to these particular students, so that they might hopefully imagine cats as having a meaningful inner life. Additionally, by relying on our students' Muslim background, which encourages them to be generous to charitable organizations, we encouraged students to fundraise for libraries and literacy and to consider everyone's right to read a book.

We are sadly hindered by a lack of YA written for and about Arabic youth, and feel that if there were more books written for Arabic youth, our students would have a better chance to connect the empathetic benefits of reading to their own lives, and students from other cultures would reap more awareness as well. However, kindness is universal, and our students reacted positively to our programs, even though most of the books we used are written by western authors.

\section{Models and resources for empathy-based programs}

For our models, we relied heavily on previous experience with public library programs. The public library sector has many programs that support empathy, whether it is reading aloud during the classic story time, reading to puppies, encouraging family reading time, homework help or by creating community spaces. We hoped to use this spirit of whole community involvement as a model, and to begin in a small way by connecting with parents to organize book discussions. We had little response and so we hope to try again next year, but we did find that students were receptive to reading together, reading to their pets, and creating and participating in story times throughout the year.

Outside the public library programs, we found an excellent resource in the new online "Empathy Library" (http://empathylibrary.com/library) to help us guide teachers who were looking for more resources. 


\section{Six Easy Library Programs that Encourage Cognitive Empathy}

\section{Program One: Make me a book! Empathy and Reader Advisory}

Partners: English Teachers or Modern Language Teachers

Class Time: Two 50 minute class periods

Reader advisory [IS THIS WHAT IT'S CALLED? SEEMS AWKWARD] improves the better you know your subject. Recommending a book is a giving, empathetic act a certain gesture of kindness. We thought students might benefit from making some of their own recommendations. Most of them lack extensive knowledge of books, however, so to put them into a reader advisory role we had to get creative.

To teach about reader advisory, students were given an introduction that asked them to consider who they make recommendations to about video games and television shows and why. Next, Year 8 students were paired with each other in teams of two. With the help of the teachers, we ensured that students did not know each other well and were from different classes. Their task: to recommend an imaginary book to that person that they would like based on a survey of interests (Appendix 2). We allowed the students to come into the library and sit where they wanted, then divided them up to be as diverse as possible. After giving students plenty of time to get to know each other, during a second lesson each student was given time to create an imaginary book for the other student. They were given materials for the book, and were asked to come up with a title, a synopsis, and a few good images for the cover.

The results were displayed the next week, and students were very excited to see the books created for them. One student brought in manga for his new partner and said "I've got to give him this book Miss because we both liked this show."

This lesson is easily adaptable for the modern language department as well.

\section{Program Two: Book Choices and Displays}

Partners: English Teachers, students

Class Time: None

Fictional narratives, especially classics, have been shown to have a positive effect on developing empathy (Bal and Veltcamo 2013). Adult readers know that the literary canon is full 
of books that encourage seeing the world from another perspective, be it Hester Prynne or Humbert Humbert, great literature elicits compassion for our shared human frailties.

However, for a young adult librarian teaching Arabic EL students English as a second language, many of the classics that encourage empathy for outsiders are not the best choices for our students' reading levels and conservative backgrounds.

We therefore came up with a short, developing list of books that have empathy as a major theme. This list was delivered to staff and students, and teachers who chose to read any of the books with their classes were invited to special library lessons and provided with resources and lesson ideas. These books were also incorporated into monthly book promotions. We feel there is a need for a more definitive list, and for research into what young adult literature would elicit empathy.

To accompany the list, we did a book promotion display that asked the students: What would it be like to be me? And then gave examples of the different struggles faced by heroines and heroes from texts. For example, "A girl in Afghanistan who disguises herself as a boy so she can work to feed her family?" Was accompanied by a picture/QR code of Deborah Ellis's The Breadwinner. The next month, students made footprints based on characters read about in their English classes and displayed them in the library, with quotes from major characters under a "walk in our shoes" theme.

\section{Program Three: Who will YOU read with?}

Partners: Students, parents

Class Time: None

After posting pictures of various staff members reading with each other and their families, students were challenged to read as many books as they could in one month with their families or friends. They could read in groups of up to four and completed forms that directly asked students to consider the perspectives of each person in their group. We were not sure if we would have any participation, because the challenge was voluntary and did not come with any certain reward beyond appreciation. However, the library was bustling with students talking about their shared books, and many forms were turned into our front desk. Our favorite anecdote: Jessim in year 9 read Percy Jackson with his little brother in year 6 , and told us he was feeling a little irritated because "his brother wanted to read with him every night" and now "wants to read the whole series." 89 forms were completed and turned into the library. Students even partnered with students they did not know well but were reading the same books, so new connections were made. 


\title{
Program Four: Reading proud and Reading aloud: Book Buddies
}

\author{
Partners: Primary School \& English Teachers
}

Class time: Up to four 50 minute class periods

Struggling young men in year 10 classes were asked if they would mind helping some year 3 students read more. First, the boys were given a library lesson on "How to read aloud and why you should." The presentation featured good looking Arabs in traditional dress reading to their children and reading with their friends, and emphasized that one way to be a good father in the future might be to read to your children. Next, the students were instructed on reading techniques including predicting, reading with expression and making connections between the readers and the text, and were then asked to practice reading simple texts with each other.

Over the next two weeks, students practiced reading children's books. All texts came with a recording so that students could model the reader and follow along with the text. Since many of the boys had reading scores that were at a year 3 or year 4 level, but we lack the high interest easy read texts appropriate for their age, these "easy" books gave the year 10 classes a reason to practice and develop their own literacy, unbeknownst to them, without compromising their self-esteem. Empathy for the younger students, some of whom were cousins and/or siblings, as well as a desire to entertain the young ones overshadowed their reluctance to read, and their English teacher remarked that "they have not been so excited about anything all year."

For the year 3 students, having the older boys read to them was quite enjoyable, and several of the young students requested specific books be read to them. Whether literacy fostered empathy or empathy fostered literacy in this case requires further research, but the results of such an easy activity were quite beyond expectations.

\section{Program Five: Where do your words fly? Kindness in thoughts and action.}

Partners: Arabic or English Staff

Class Time: 1 class period.

After being told the eastern European parable about the man who gossips unwisely and realizes he has made a mistake, only to learn that his words have spread and are like feathers from a broken pillow and that he can quite possibly never collect them again, students were asked to consider something for which they admired someone else but had never expressed 
aloud. To make sure they were honest and to keep anyone from being embarrassed or from feeling that they were not admitted, they were asked not to name the person they admired, but to just write down a compliment. They were then given paper "feathers" that said: The person I am thinking of is admirable because:

Students created a myriad of compliments, most of which were vague enough to apply to anyone. We placed the kind words around the library and students liked to speculate to whom the compliments were directed. They were written in both Arabic and English.

This lesson can also be easily adapted to teach about cyber bullying using technology, text messages and twitter in lieu of paper.

\section{Program 6: Story time for young teens}

We offer teachers the option of signing up for a daily "Teen Storytime" where we read to year 7 and 8 students books such as Gregor the Overlander or A Tale of Desperaux. The important part of teen story time is one that all primary teachers are familiar with and that secondary students can enjoy as well: creating participation with text. However, as analysis becomes more sophisticated, sometimes secondary students get caught up in what is the right answer and not whether or not they enjoy or connect with the text. So we let students sprawl out on bean bags or lay on chairs to create a calm, comfortable atmosphere. The important part is that the reader stops to ask plenty of questions that connect the students directly with the narrative and empathy. "Do you have a sister? If you were Gregor, how would you feel after she disappeared?" or "Do you ever feel like you do not fit in with your family? How does love make Desperaux brave?" "How would you help Desperaux?" The more advanced the class, the more sophisticated the text and questions for story time, but the questions that connect to students' lives, and particularly the things they care about, bring about a positive association between caring for others and reading.

\section{Student Volunteer Programs that Foster Empathy}

Doha, Qatar could be labeled a place with few volunteer opportunities. According to a survey conducted at the beginning of the school year, most students do not volunteer in the community, although they are interested in doing so. While recognizing that students who volunteer might be predisposed to be empathetic anyway, our hope was that by training a small group of students to promote an atmosphere conducive to reading and helping, they would influence other students with less motivation to read or volunteer. 
We received over 70 applications from potential student volunteers, and interviews took several weeks to conduct. Because of the gender segregation rules and time limitations at our school, all of our volunteers were female students.

Several students who were not chosen to be monitors came in to help anyway, and were eventually added to replace students who did not show up for their shifts. In this way, we were able to recruit a group of fifteen students, called the "library monitors" who were dedicated to helping throughout the school year.

Additionally, we tapped our school CAS program for more student volunteers from our school's AS and IB programs. We found three ways that library volunteerism strengthened the connection between empathy and literacy: 1) Enforcing a communal and safe space to read; 2) Consideration of day-to-day library operations including reader advisory; 3) Awareness of other library communities and students in need of books.

\section{Volunteer Mandate One: Creating the Space}

Every librarian wants the library to be a safe, comfortable space for all students. However, we have found that during breaks, when the library is very busy, it can be difficult to ensure that the library atmosphere is pleasant for all students. Although the library is often a refuge from the bullying that goes on in school hallways and playgrounds, our two simple rules, "No eating!" and "Be nice!" are not always followed. Students will still occasionally insult each other, and disagreements will erupt. In order to counteract this growing problem, we asked our student volunteers to assist us in ensuring that students maintain kindness and politeness toward each other during all unstructured library time. We found that by appointing other students to reprimand bullying behaviors, we avoided embarrassing students who are bullied, and instead gave them the support of their peers. Students who are in charge of the library atmosphere are the oldest students at our school and therefore have more confidence in disrupting negative behaviour. This also solved the problem of bullying in Arabic, since most students but only one staff member can speak Arabic.

These Library Monitors were instructed to stop any conversations or behaviors that attacked students for their race, religion, or country of origin and to report to staff any directly insulting or potentially violent behaviour. The results were evident after only two weeks: after the monitors were trained and in place, there were no more physical fights and negative behaviors were quickly averted. IB and AS monitors were especially good at resolving conflicts, and might have been peacemakers between their younger siblings at home. 
We chose Library Monitors who were avid readers, and asked them to help with reader advisory. They were asked to pick their five favorite books and to recommend them by creating a bookmark with their favorite quote from the book, their year group and initials. The bookmarks were then placed in the corresponding books. Other students would look for these bookmarks, and were able to find books they liked more readily.

Students were also asked to share their favorite books with other students, and were given their own shelf for "Student Staff Picks."

\section{Volunteer Mandate Two: Consideration of Day to Day Operations}

In becoming more involved in clerical work in the library, such as stamping and labeling books, many students found more opportunities to find interesting books to read, and were able to adopt some of the empathetic values that are inherent in librarianship, such as the kindness of giving a younger student a book that was meaningful to them at some point. They were also routinely thanked with specific praise such as "Thank you Salma, because you stamped these books I was able to finish a neat lesson for Year 7 students" or "Thank you Hajer, because you put that book away I was able to help this student research a paper." We believe that by specifically praising the students they were better able to understand why their volunteer work is important.

Every student who became a library monitor dreamed of the big day when they would be allowed to check out books using the amazing librarian ray-gun, i.e. barcode scanner. However, we wanted to be careful that in allowing students to check out material they would not comment on or repeat to others what material was being circulated to whom.

Students were therefore trained for two 20 minutes sessions about privacy, and its role in an international environment. Students were asked to imagine themselves as a person from a different culture, and how what is right for one family might not be so for another family.

Censorship is still widely practiced in the Gulf region, and our library follows strict guidelines for collection development and requires parental permission for many checkouts. While some of our material is censored at customs and young adult books are restricted to IB students and students with parental permission, we still wanted to give students an opportunity to think about the library as a place where free speech is important both for the transmission of knowledge and as a means to respect the viewpoints of others. 


\section{Volunteer Mandate Three: Everyone has a right to read.}

After teaching students about censorship, banned books and privacy, Fatima, a year 10 student who recently participated in a food drive for the Philippines asked: "What is the point of all this if so many people can't eat, and will never have books anyway?" The relief education provides to poverty was something that needed further discussion! Students were asked to research charities involved in giving books, and to consider how education effects quality of life. Then we asked students if they could think of solutions, and they decided to fundraise to help a library in a poorer country.

Recently, the French students had been working in the library on sending letters to a Haitian library, and so the volunteers decided to extend this into a fund raising campaign for the ARAKA library in Haiti. Since they had contacted the students in Haiti, they felt more of an interest and connection with them than they might have otherwise.

After discussing it among themselves, they came up with a plan. Once a month, they would do a video game tournament in the library to fundraise for another library. They would also ask students who were returning books late if they would like to make a small donation.

While the amount raised was relatively small, the discussion it created about reading was quite valuable. Most charitable giving done by the students involved food relief for natural disasters and giving books was seen as a luxury. By thinking about reading as a right that not all young people have, students were able to consider the important effect of education on quality of life and see books as something valuableand giving them to others as a charitable and fun activity!

\section{Volunteer Programs: Results and Conclusion}

Our positive anecdotal feedback was strong and sincere for the Library Monitor project, and we counted 32 instances of kind behavior toward other students in the form of book recommendations, bullying prevention and altruism. We hope to continue to develop a formal program with student volunteers.

However, it is time consuming to ensure that volunteer training is reinforced, and that volunteers are given frequent feedback and clear direction. Additionally, despite extensive training, we found many, many shelving disasters! 


\section{Resources for Staff: Improving Empathy for Staff Members}

Due to language barriers, our Arabic and English staff rarely interact, and stay on opposite sides of the staff room at all times. The only place where this segregation is an exception is in the library; due to the open space that is more conducive to cooperation and the presence of a friendly bilingual staff member, we are able to bridge many of the communication problems experienced by other staff.

We worried that students would notice that their teachers do not talk to each other often. We therefore organized staff library insets so that the different ethnicities would have ample opportunity to interact and learn from each other. Our first opener: What book would you recommend to someone who wanted to learn more about your culture?

We hope we can find more ways to create a welcoming space for team teaching, and to create positive interactions for teachers.

\section{Room for Improvement}

Unfortunately, empathy is on the decline among young people, at least in the United States (Zaki 2010).

This is not news to most teachers, but there is still much we can do as librarians to help students become more empathetic. One librarian suggests using primary source material to give students a direct connection to the text (Stripling 2012). Many librarians teach digital citizenship and cyberbullying, which are skills that would be improved by an empathy driven library programs.

One concern we had is that fictional narratives, specifically those on television, contribute to "just world beliefs" (Appel 2008) by virtue of their easy and certain resolutions. Any reading is good reading in our library, but we would like to promote books that are both entertaining and thought provoking.

While young adult literature does handle complexity and unfairness, it seems that the books that fly off the shelves are usually not ones that challenge the fairness of the world or have empathy as a major theme. Additionally, the positive effect of reading on empathy was shown only to occur when the reader is "emotionally transported "(Bal and 
Veltcamp 2013). As many school librarians know, it is a challenging enough task just to get all the students to read for pleasure, let alone ensure they are "emotionally transported."

If students are not reading books that disturb them, or that push them toward changing and improving the world, they might not experience the benefits of the reading-empathy connection. Indeed, a survey conducted in the United States found that among students aged $15-25$ (Safrit 2002) only $40 \%$ felt that they had a responsibility to change and improve society.

We hope that by providing empathy-based literacy lessons and programs, encouraging the values of librarianship and giving students an opportunity to volunteer, that we can at least make our library a kinder place to be, and start the long process of cultivating more empathy-centered lessons, resources and programs. 


\section{Works Cited}

Bal PM, Veltkamp M (2013). How Does Fiction Reading Influence Empathy? An Experimental Investigation on the Role of Emotional Transportation. PLoS ONE 8(1): e55341. doi:10.1371/journal.pone.0055341

Castano, Emanuele and Comer, David. (2013.) "Reading Literary Fiction Improves Theory of Mind" Science 18 October 2013: 342 (6156), 377-380.Published online 3 October 2013[DOI:10.1126/science.1239918]

Collins, Suzanne. Gregor the Overlander. New York: Scholastic, 2003.

Dicamillo, Kate. The Tale of Despereaux. Cambridge, Mass: Candlewick Press, 2003.

Frans B.M. deWaal (2008). "Putting the Altruism Back into Altruism: The Evolution of Empathy".Annual R Annu. Rev. Psychol. 59 (59): 279-

300. doi:10.1146/annurev.psych.59.103006.093625. PMID 17550343.

Lam, C. B., Solmeyer, A. R., \& Mchale, S. M. (2012). Sibling relationships and empathy across the transition to adolescence. Journal of Youth and Adolescence, 41(12), 165770. doi:http://dx.doi.org/10.1007/s10964-012-9781-8

Simone G. Shamay-Tsoory, Judith Aharon-Peretz and Daniella Perry (2009). "Two systems for empathy: a double dissociation between emotional and cognitive empathy in inferior frontal gyrus versus ventromedial prefrontal lesions". Brain 132 (3): 617627. doi:10.1093/brain/awn279.

Safrit, D. R. (2002). Developing effective teen--adult partnerships through volunteerism: Strengthening empathy, engagement, empowerment, and enrichment. Journal of Volunteer Administration, 20(4), 21-26.

Stripling, B. K. (2012). Fostering empathy: Who cares? School Library Monthly, 28(4), 20-22.

Jamil, Z. (2010). "What, Me Care? Young are less empathetic." Scientific American, Mind \& Brain January/February 2011. 


\section{Appendix 1}

Caring in your classroom

While there are many thousands of books that inspire empathy, here are a few selections for young people where empathy is a significant, driving force in the work and we hope will encourage student discussion about kindness. For more ideas see the empathy library http://empathylibrary.com/library

\section{Fiction}

${ }^{*}$ Corimer, Robert. The Chocolate War. New York: Pantheon Books, 1974.

*Dick, Phillip K. Do Androids Dream of Electric Sheep?

${ }^{*}$ Greene, John. The Fault in Our Stars. New York : Dutton Books, ๑2012.

Lee, Harper. To Kill a Mockingbird. Philadelphia : Lippincott, ๑1960.

Palacio, R.J. Wonder. New York: Alfred A. Knopf, 2012.

Paterson, Tabitha. The Bridge to Terabithia. New York: Harper Trophy, 1987

Speare, Elizabeth. The Witch of Blackbird Pond. Boston: Houghton Mifflin, 1958

Spinelli, Jerry. Maniac Macgee. Boston: Little, Brown, 1990.

Vicary, Tim. The Elephant Man. Oxford: Oxford University Press, 1989.

*Vigan, Delphine. No et Moi. Paris : J-C Lattès, (02007.

White, E. B. Charlotte's Web. New York: Harper Collins, 1952

\section{Non-Fiction}

*Grealy, Lucy. Autobiography of a Face. New York: Perennial, 1994.

*Kidder, Tracy. Mountains beyond Mountains. New York: Random House, 2003.

${ }^{*}$ Kristof, Nicholas and Wudunn, Cheryl. Half the Sky: Turning Oppression into

Opportunity for Women Worldwide. New York : Alfred A. Knopf, 2009.

Makos, Adam and Alexander, Larry. A Higher Call: the incredible true story of combat and chivalry in the war-torn skies of World War II. New York: Berkley Books, 2013.

\section{Short Stories}

"Le Guin, Ursula. "The ones who walk away from Omelas" . Mankato, Minn: Creative Education, 1993.

Matheson, Richard. "Button, button" from Button, Button: Uncanny Stories. New York : Tor, 2008.

Silverberg, Robert. "To See the Invisible Man" from The Best of Robert Silverberg Boston: Gregg Press, 1978.

${ }^{*}$ Recommended especially for older students with no censorship concerns 


\section{Appendix 2}

\section{HEE.P! I NEED $\mathcal{A}$ BOOK! Reader Advisory Assignment}

Your IV died on the same day ALIo the matls in Qatar closed down! Oply your partrer car save you from death by

$$
\text { boredom..... }
$$

1. What is your pame ard where gre you from?

2. What is something furny that happered to you or someore you know?

3. Who are the most important people in your life?

4. What is your froorite food?

5. What kind of movies do you like? (action, cartoon, comedy)

6. What is the bast book you read that you liked?

7. Why dild you like that book?

8. Do you like horror stories or adverture stories better?

9. If horror storees, what frighteras you and why?

10. If adverture stories: who Is your hero and why? 


\section{Recommending Student}

Based on your interview with your paptrer, create an imaginary book that your partreer would like to read. Include a book cover, an arthor, titbe and summary on the back of the book that tells what the book is about in 1 to 2 paragreaphs.

Extreg Credit: Create a table of contents with chapter names! 
